\title{
The Baeyer-Villiger reaction of 23-oxosapogenins
}

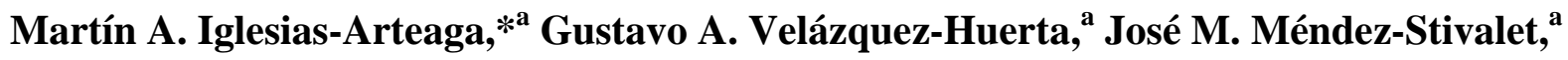 \\ Annia Galanob, and J. Raúl Alvarez-Idaboy* a \\ ${ }^{a}$ Facultad de Química, Universidad Nacional Autónoma de México \\ Ciudad Universitaria, 04510 México D.F., México. ${ }^{b}$ Instituto Mexicano del Petróleo, Eje Central \\ Lázaro Cárdenas 152, 007730, México D. F., México \\ E-mail: martín.iglesias@servidor.unam.mx, jidaboy@prodigy.net.mx
}

\section{Dedicated to Professor Eusebio Juaristi on occasion of his $55^{\text {th }}$ birthday}

(received 8 Mar 05; accepted 22 Apr 05; published on the web 24 Apr 05)

\begin{abstract}
The Baeyer-Villiger reactions of 25R- and 25S-23-oxosapogenins with MCPBA produced a mixture of bisnorcholanic $22 \rightarrow 16$ lactones and pregnan-16,20-diol carbonates. The postulated mechanism explains the reaction times in terms of the transition states for the peroxyacid attack. The explanation of the regioselectivity of the studied reaction relays on the conformational preference of the Criegee's intermediate. Reaction barriers calculated using the semiempirical PM3 method justify the observed reaction times.
\end{abstract}

Keywords: Baeyer-Villiger reaction, oxosapogenin, semiempirical PM3 calculations

\section{Introduction}

For a long time steroid sapogenins have been used as starting materials for the synthesis of different steroidal drugs, ${ }^{1}$ and more recently on the synthesis of ecdysone, ${ }^{2}$ spirostanic and furostanic analogues of brassinosteroids with modified side chains. ${ }^{3}$ All synthetic procedures relay on the degradation or modification of the spirostanic side chain. The reactivity of the spirostanic side chain was extensively studied during the mid part of the last century. ${ }^{4}$ More recently, new transformations have been reported, ${ }^{5,6}$ some of these reactions have been reported to produce the cleavage of the spiroketal side chain to the C-22 $\rightarrow 16$ lactone moiety characteristic of bisnorcholanic lactones. ${ }^{6}$

Bisnorcholanic lactones have called the attention of scientists due to their biological prop-

erties. ${ }^{7}$ Early reports show that such compounds can be produced in low yield by treatment of the corresponding steroid sapogenin with $\mathrm{CrO}_{3}, \mathrm{HNO}_{3}$ or as a byproduct of reaction with $\mathrm{NaNO}_{2}$ and $\mathrm{BF}_{3} \cdot \mathrm{Et}_{2} \mathrm{O}$ in acetic acid. ${ }^{8}$ The conversion of solasodine and tomatidine into the corresponding 
lactones have been also reported. ${ }^{9}$ New synthetic alternatives to the mentioned lactones are always desirable. Herein, we report on the Baeyer-Villiger reaction (BV) of 23-oxosapogenin acetates as an alternative to the synthesis of bisnorcholanic lactones and as a source of steroid diversity.

\section{Results and Discussion}

Sapogenin acetates 1a (3-epismilagenin acetate) and $\mathbf{1 b}$ (sarsasapogenin acetate) were prepared from the parent sapogenin using the standard $\mathrm{Ac}_{2} \mathrm{O}$ /pyridine procedure. Rockogenin acetate 1c can be easily prepared by $\mathrm{NaBH}_{4}$ /methanol reduction of hecogenin followed by acetylation and fractional crystallization as we have previously described. ${ }^{10}$

Treatment of sapogenin acetates 1 a-c with $\mathrm{NaNO}_{2}$ and $\mathrm{BF}_{3} \cdot \mathrm{Et}_{2} \mathrm{O}$ followed by chromatography in neutral $\mathrm{Al}_{2} \mathrm{O}_{3}$ (Brockmann activity III) led to the desired 23-oxosapogenin acetates 2a-c and a minor amount of the corresponding bisnorcholanic lactones 3a-c, (Scheme 1).

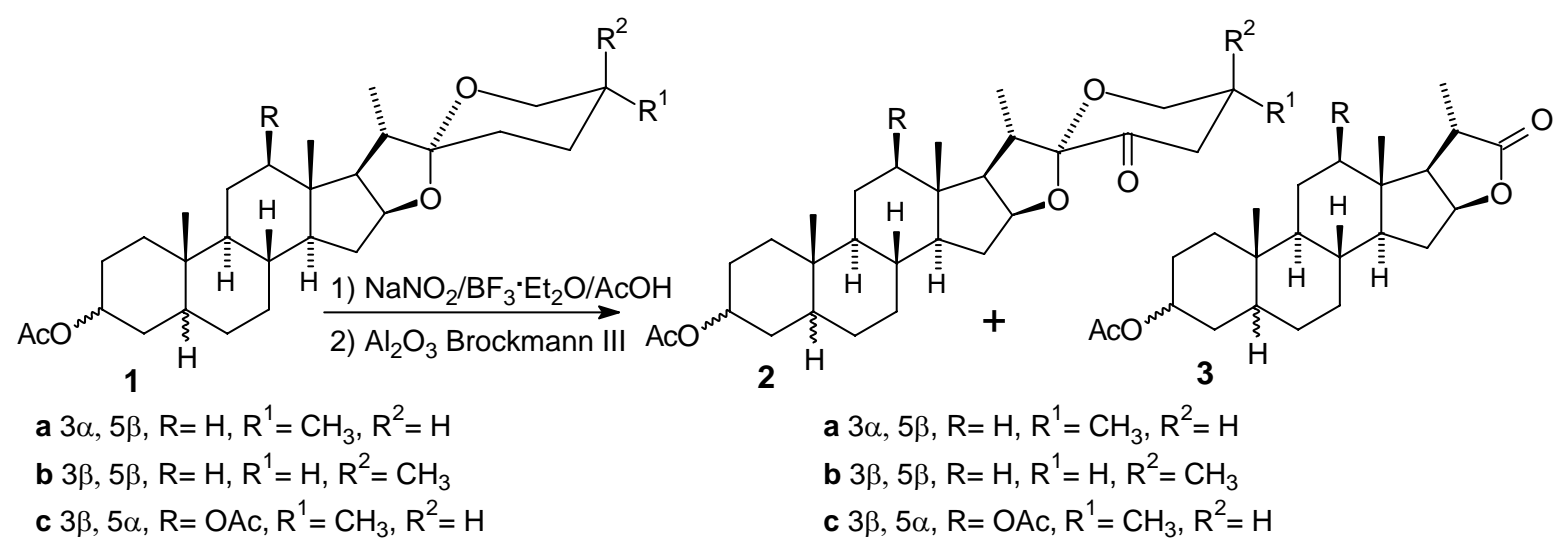

\section{Scheme 1}

The ${ }^{1} \mathrm{H}$ NMR spectra of the 23-oxosapogenins (Table 1) show the downfield shift of the signals of the diasterotopic H-26 ax. and H-26 eq. in both $25 R$ and $25 S$ series, which together with the deshielding of $\mathrm{H}-16$ and $\mathrm{H}-20$ have been outlined as the main effects of the presence of a carbonyl function at C-23. ${ }^{11}$ Downfield shift of $\mathrm{H}-26$ have been attributed to magnetic anisotropy of the carbonyl function meanwhile deshielding of $\mathrm{H}-20$ have been rationalized as a result of the combination of a $\delta$-syn interaction between $\mathrm{H}-20$ and the carbonylic oxygen and magnetic anisotropy of the $\mathrm{C}=\mathrm{O}$ bond. For comparison see ${ }^{1} \mathrm{H}$ NMR spectra of rockogenin acetate (1c) and 23-oxorockogenin acetate (2c), (Figures 1 and 2). 


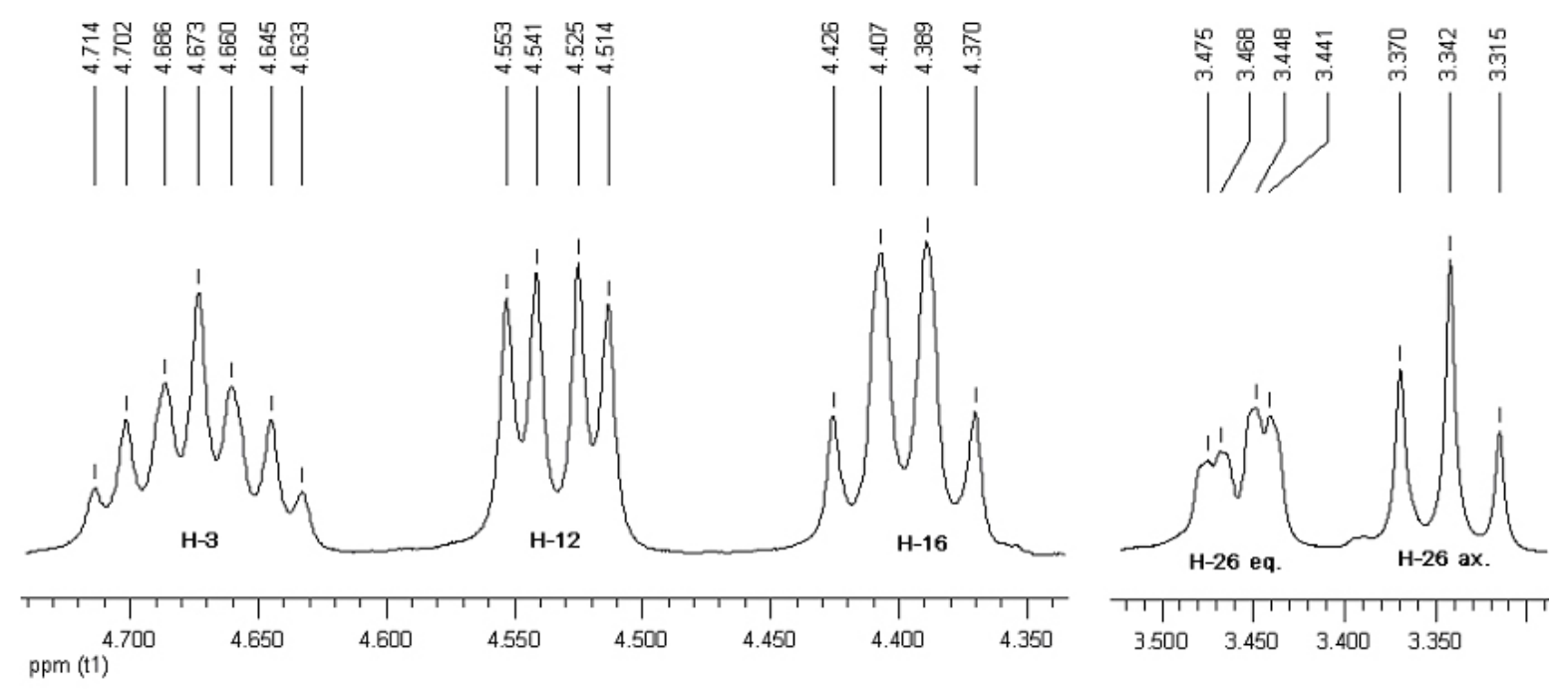

Figure 1. Fragment of ${ }^{1} \mathrm{H}$ NMR spectrum of rockogenin acetate (1c).
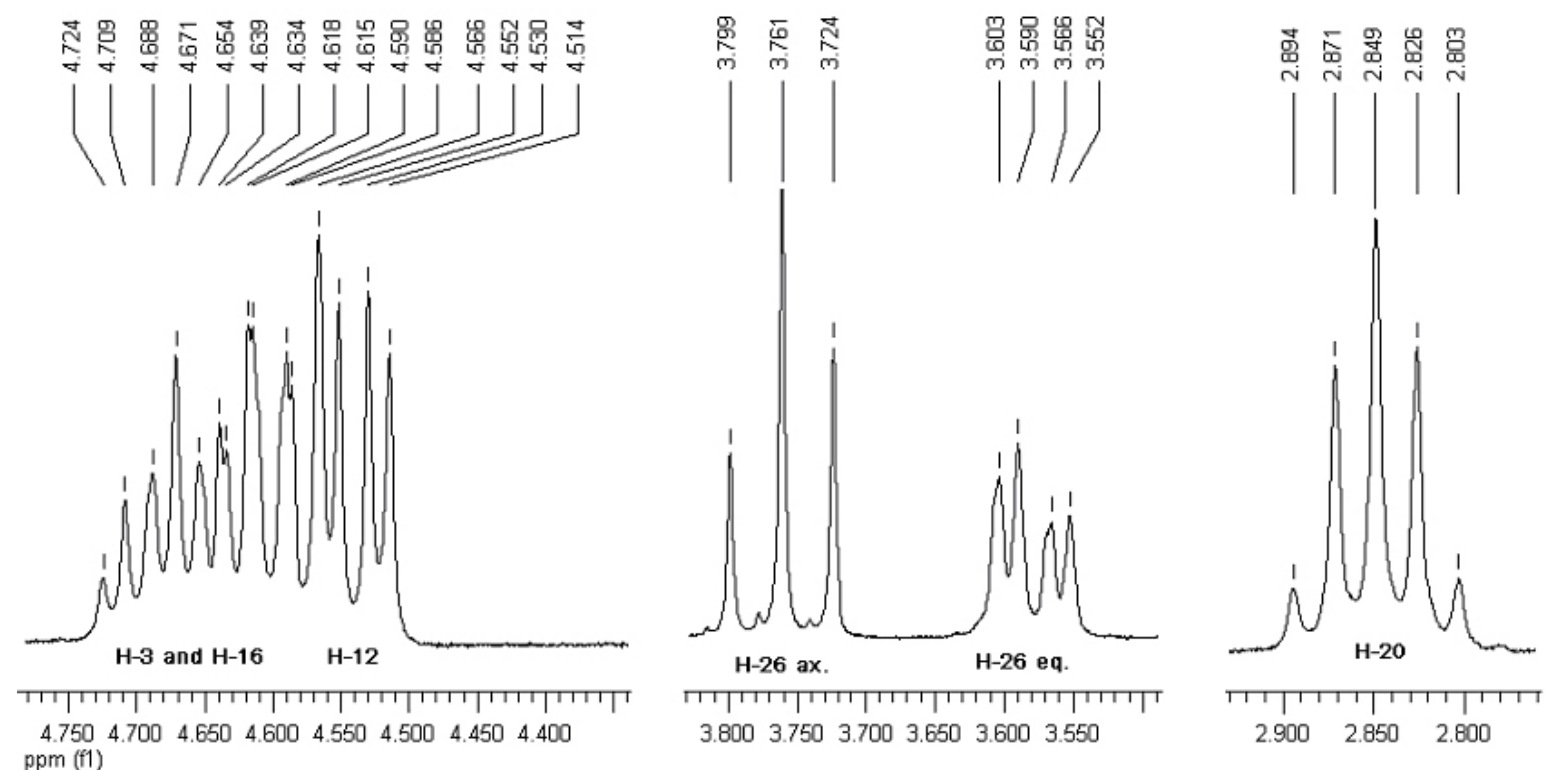

Figure 2. Fragment of ${ }^{1} \mathrm{H}$ NMR spectrum of 23-oxorockogenin acetate (2c).

In addition to the signal corresponding to the carbonyl function introduced at C-23, the main characteristics of the ${ }^{13} \mathrm{C}$ NMR spectra of 23-oxosapogenins have been outlined as: a) shielding of C-20 (produced by van der Waals compression of $\mathrm{H}-20$ due a $\delta$-syn interaction with the carbonyl function at C-23), b) deshielding of C-24 ( $\alpha$ to the carbonyl function at C-23) and c) deshielding of $\mathrm{C}-25$ due to the lost of a $\gamma$-diaxial interaction with $\mathrm{H}-23$ axial, ${ }^{11}$ (all compared with the corresponding steroid sapogenin, see Table 2). 
The ${ }^{1} \mathrm{H}$ NMR spectra of bisnorcholanic lactones 3a-c (Figure 3) are characterized by the absence of the signals corresponding to the protons 23 to 27 and the downfield shift of the signals corresponding to H-16 (now part of the lactone moiety) and H-21 (due to magnetic anisotropy of the carboxy group). Shielding of H-20 may be attributed to a combination of magnetic anisotropy of the carboxyl and the absence of the deshielding interactions present in the 23oxosapogenins between $\mathrm{H}-20$ and the carbonylic oxygen. (Compare with the corresponding 23oxosapogenin, see Table 1).

The ${ }^{13} \mathrm{C}$ NMR spectra of bisnorcholanic lactones 3a-c are characterized by the absence of the signals corresponding to C-23 to C-27, the downfield shifts of C-22 (now carboxy), C-21 and C-20 and the upfield shift of C-18 and C-17. (Compare with the corresponding 23-oxosapogenin, see Table 2).

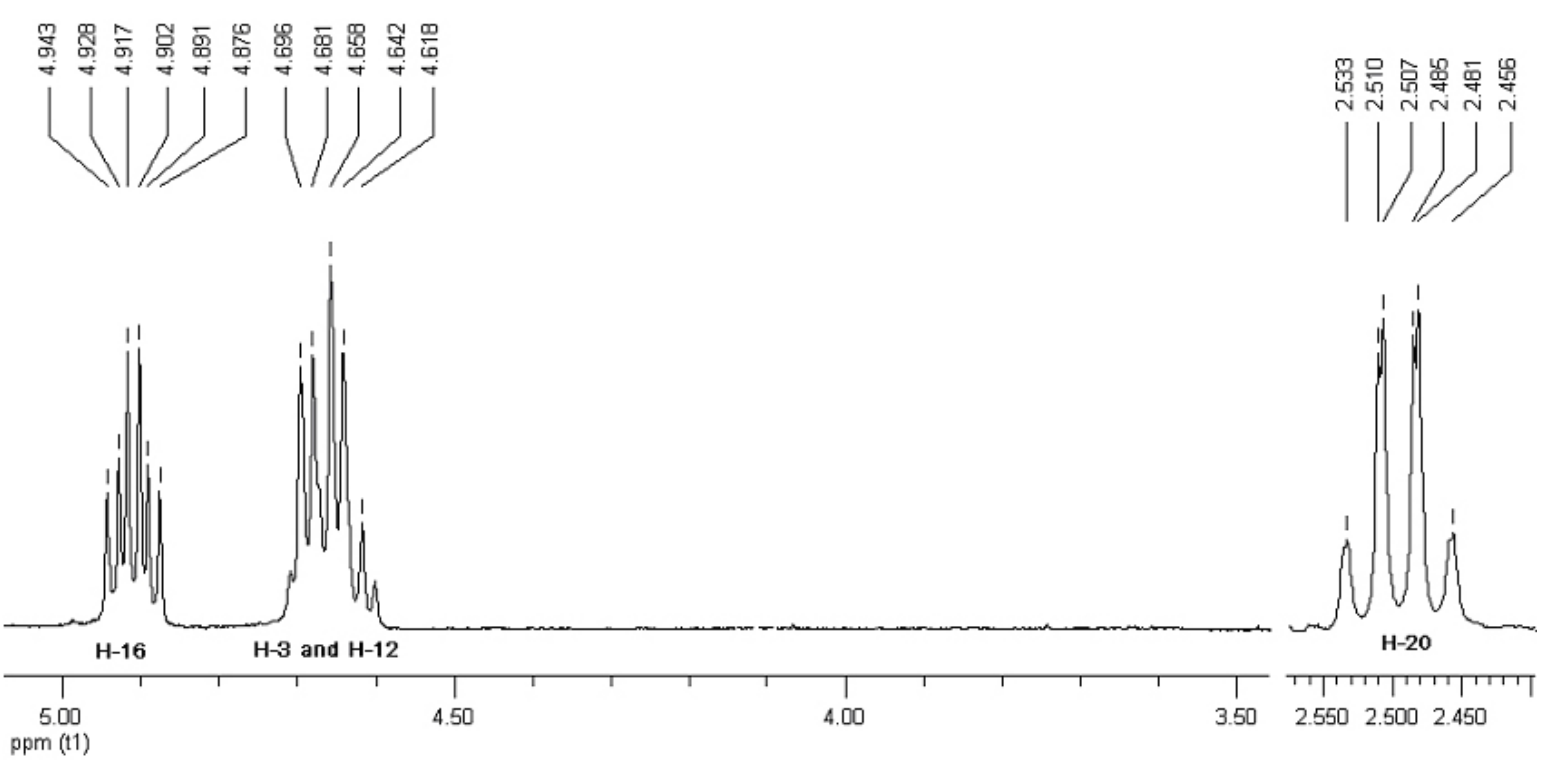

Figure 3. Fragment of ${ }^{1} \mathrm{H}$ NMR spectrum of bisnorcholanic lactone 3c.

Treatment of the 23-oxosapogenins with MCPBA afforded a mixture of the bisnorcholanic lactone and the cyclic carbonate after long reaction times (4 weeks for the 25R-ketosapogenins 2a and 2c and 9 weeks for 25S-ketosapogenin $\mathbf{2 b}$ ), (see Scheme 2). The carbonates may be unequivocally recognized in the ${ }^{1} \mathrm{H}$ NMR spectra by the new downfield signal corresponding to $\mathrm{H}$ 20 (now carbynolic) which shows correlation with the deshielded H-21 protons, (Figure 4). Additionally, downfield shift of H-18 and upfield shift of H-16 characterize these structures. (Compare with bisnorcholanic lactones, see Table 1). 


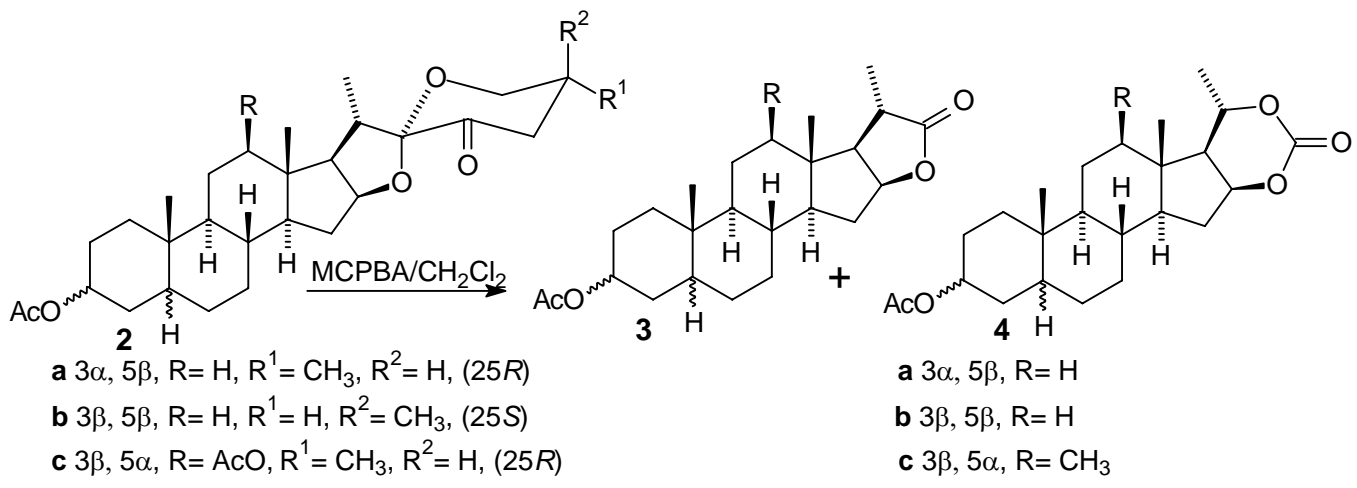

\section{Scheme 2}

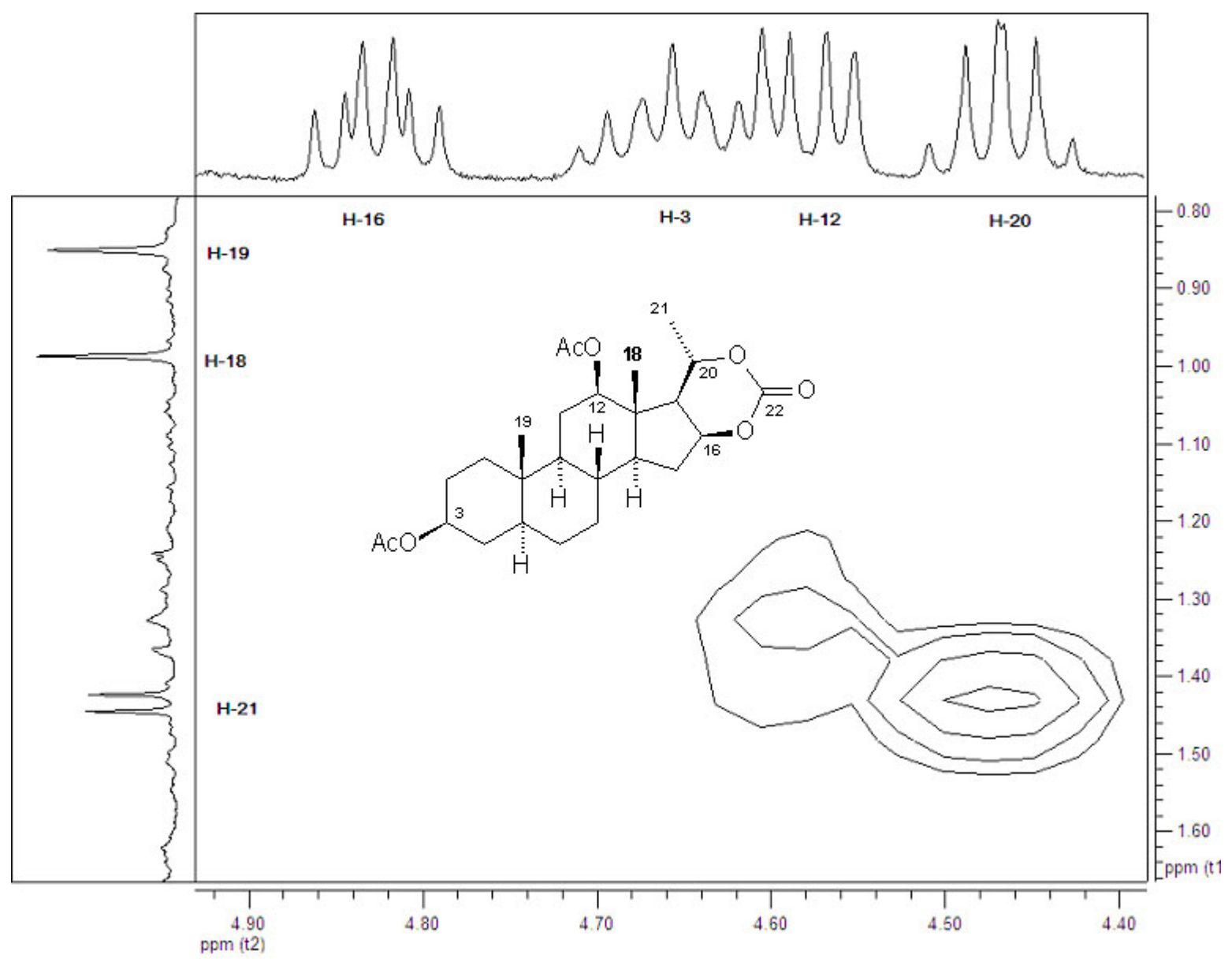

Figure 4. Fragment of H-H COSY of carbonate 4c.

The ${ }^{13} \mathrm{C}$ NMR spectra of carbonates $4 \mathbf{a}-\mathbf{c}$ are characterized by: a) the new functional signal corresponding the to the carbonate; b) the downfield shifts of C-20, C-18 and C-21; and c) upfield shifts of C-16 and C-17, (Compare with bisnorcholanic lactones, see Table 2 and Figure 5). 


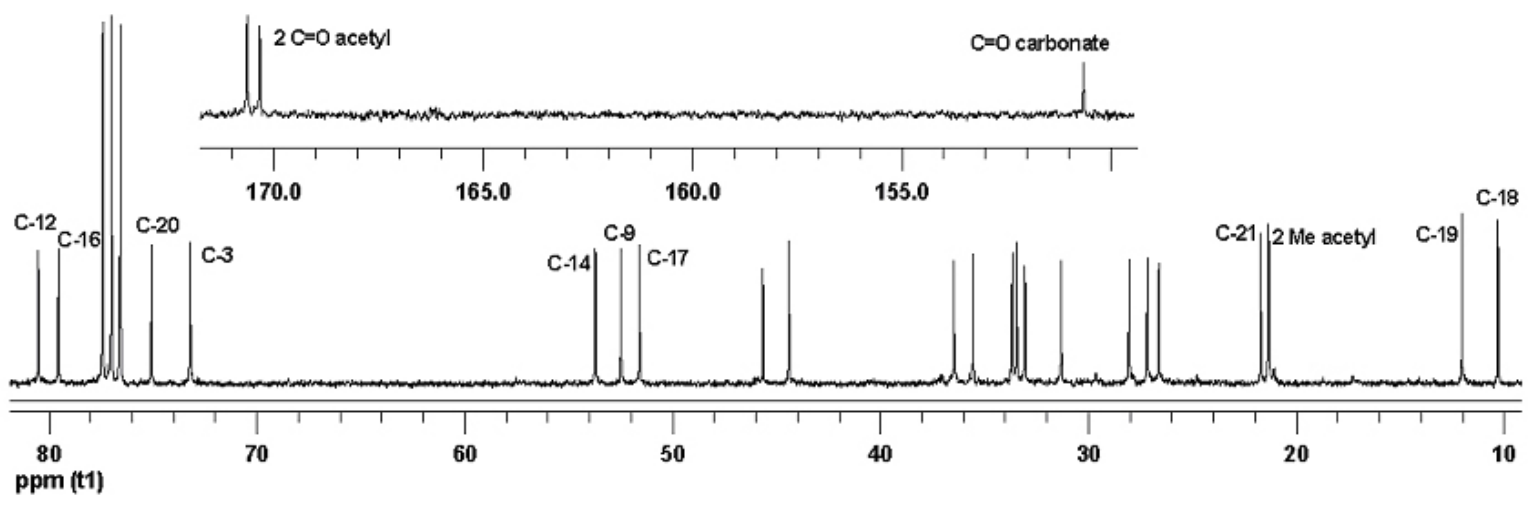

Figure 5. ${ }^{13} \mathrm{C}$ NMR spectrum of carbonate $4 \mathrm{c}$.

Table 1. ${ }^{1} \mathrm{H}$ NMR selected signals of sapogenin acetates (1), 23-oxosapogenins (2), bisnorcholanic lactones (3) and carbonates (4)

\begin{tabular}{lllllllllllll}
\hline & 1a & 2a & 3a & 4a & 1b & 2b & 3b & 4b & 1c & 2c & 3c & 4c \\
\hline H-16 & 4.38 & 4.59 & 4.95 & 4.73 & 4.39 & 4.60 & 4.92 & 4.77 & 4.37 & 4.67 & 4.91 & 4.83 \\
H-18 & 0.74 & 0.74 & 0.74 & 0.86 & 0.75 & 0.76 & 0.72 & 0.88 & 0.82 & 0.84 & 0.82 & 0.98 \\
H-20 & $1.86^{\text {a }}$ & 2.86 & 2.58 & 4.43 & $1.81^{\text {a }}$ & 2.88 & 2.56 & 4.45 & $1.86^{\mathrm{a}}$ & 2.85 & 2.50 & 4.47 \\
H-21 & 0.95 & 0.93 & 1.32 & 1.45 & 1.06 & 1.06 & 1.30 & 1.46 & 0.90 & 0.94 & 1.24 & 1.42 \\
H-26 ax. & 3.36 & 3.77 & - & - & 3.94 & 4.26 & - & - & 3.32 & 3.76 & - & - \\
H-26 eq. & 3.47 & 3.57 & - & - & 3.29 & 3.40 & - & - & 3.43 & 3.58 & - & - \\
\hline
\end{tabular}

${ }^{\mathrm{a}}$ See reference 11.

Table 2. ${ }^{13} \mathrm{C}$ NMR selected signals of sapogenin acetates (1), 23-oxosapogenins (2), bisnorcholanic lactones (3) and carbonates (4)

\begin{tabular}{lllllllllllll}
\hline & 1a & 2a & 3a & 4a & 1b & 2b & 3b & 4b & 1c & 2c & 3c & 4c \\
\hline C-16 & 80.8 & 83.4 & 82.7 & 80.3 & 81.0 & 83.5 & 82.8 & 80.3 & 80.4 & 82.9 & 82.1 & 79.6 \\
C-17 & 62.2 & 61.8 & 59.1 & 55.4 & 62.1 & 61.8 & 59.1 & 55.3 & 61.2 & 60.7 & 57.6 & 51.5 \\
C-18 & 16.4 & 16.1 & 13.8 & 14.9 & 16.0 & 16.2 & 13.8 & 14.9 & 11.5 & 11.4 & 9.4 & 10.3 \\
C-20 & 41.7 & 34.7 & 36.0 & 74.6 & 42.1 & 35.1 & 36.2 & 74.6 & 42.1 & 35.7 & 37.1 & 75.5 \\
C-21 & 14.5 & 14.3 & 17.9 & 21.4 & 14.3 & 14.2 & 17.9 & 21.5 & 13.6 & 13.5 & 17.3 & 21.7 \\
C-22 & 109.2 & 109.8 & 181.2 & $152.0^{*}$ & 109.7 & 110.7 & 181.4 & $152.0^{*}$ & 109.2 & 109.8 & 181.0 & $150.7^{*}$ \\
C-23 & 31.3 & 201.8 & - & - & 25.9 & 202.3 & - & - & 31.3 & 201.7 & - & - \\
C-24 & 28.7 & 45.2 & - & - & 25.7 & 43.9 & - & - & 28.7 & 45.2 & - & - \\
C-25 & 30.3 & 35.8 & - & - & 27.1 & 33.7 & - & - & 30.2 & 35.2 & - & - \\
C-26 & 66.8 & 65.6 & - & - & 65.1 & 64.5 & - & - & 66.8 & 65.6 & - & - \\
C-27 & 17.1 & 17.0 & - & - & 16.0 & 17.7 & - & - & 17.1 & 17.0 & - & - \\
\hline
\end{tabular}

* Now carbonate. 
The occurrence of the observed products may be explained by a reaction path in which, after addition of the peroxyacid to C-23, migration of C-22 leads to the ortoester II that may rearrange to the lactones 3a-c or be attacked by another molecule of peroxyacid at C-22 to produce III which on migration of C-20 leads to the cyclic carbonates 4a-c, (see Scheme 4). The $20 S$ configuration of the carbonates 4a-c stems from the known fact that in BV reactions, migration occurs with retention of the configuration of the migrating group. ${ }^{12}$

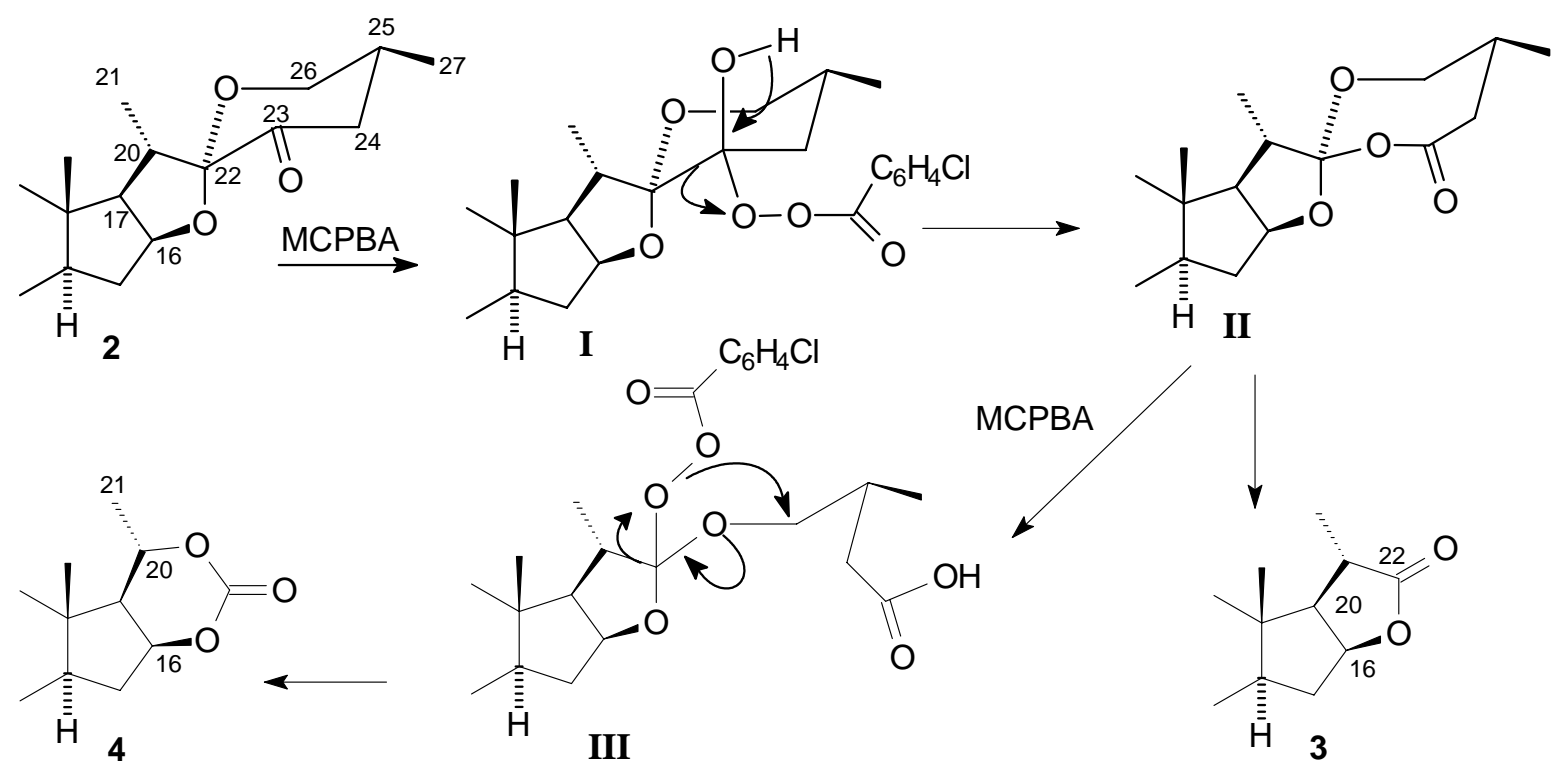

Scheme 3. Possible mechanism.

Marker and Shabica ${ }^{13}$ found that treatment of 23-oxosarsasapogenin acetate with von Baeyer persulfuric reagent (potassium persulfate, potassium sulfate and concentrated sulfuric acid) in acetic acid for 16 days led to a mixture of a bisnorcholanic lactone and a pregnan3,16,20 triol, (Scheme 5). The proposed mechanism postulates that in such acidic conditions, the spiroketal side chain is opened to the $\alpha$-diketone IV which produces BV reactions to a mixture of the anhydride $\mathbf{V}$ and the ketoester VI. Saponification followed by acidification leads to a mixture of the pregnan-3,16,20 triol and the bisnorcholanic lactone.

A similar mechanism may be postulated for the studied BV reaction with MCPBA, the occurrence of observed carbonates can be explained only if an additional BV step from VI to VII is accepted. In our case, the following facts allow us to discard Marker's open chain mechanism:

- The strong acidic media derived from the von Baeyer reagent used by Marker may produce both, the opening of the spiroketal side chain and acid catalysis resulting in shorter reaction times. By contrast, the reaction conditions used in our case (MCPBA in $\mathrm{CH}_{2} \mathrm{Cl}_{2}$ ), are not acid enough to produce opening of the spiroketal side chain or acid catalysis.

- If the observed BV reaction with MCPBA acid follows the open chain mechanism, steric hindrance to the attack of the peroxyacid would be minimized and no differences between the re- 
activity of $25 R$ and $25 S$ compounds should be encountered. The significant difference between the reaction times on the $25 R$ and $25 S$ series, accounts for a closed chain mechanism in which the axial position of the 27-methyl group hinders the nucleophilic attack of the peroxyacid to the carbonylic C-23.

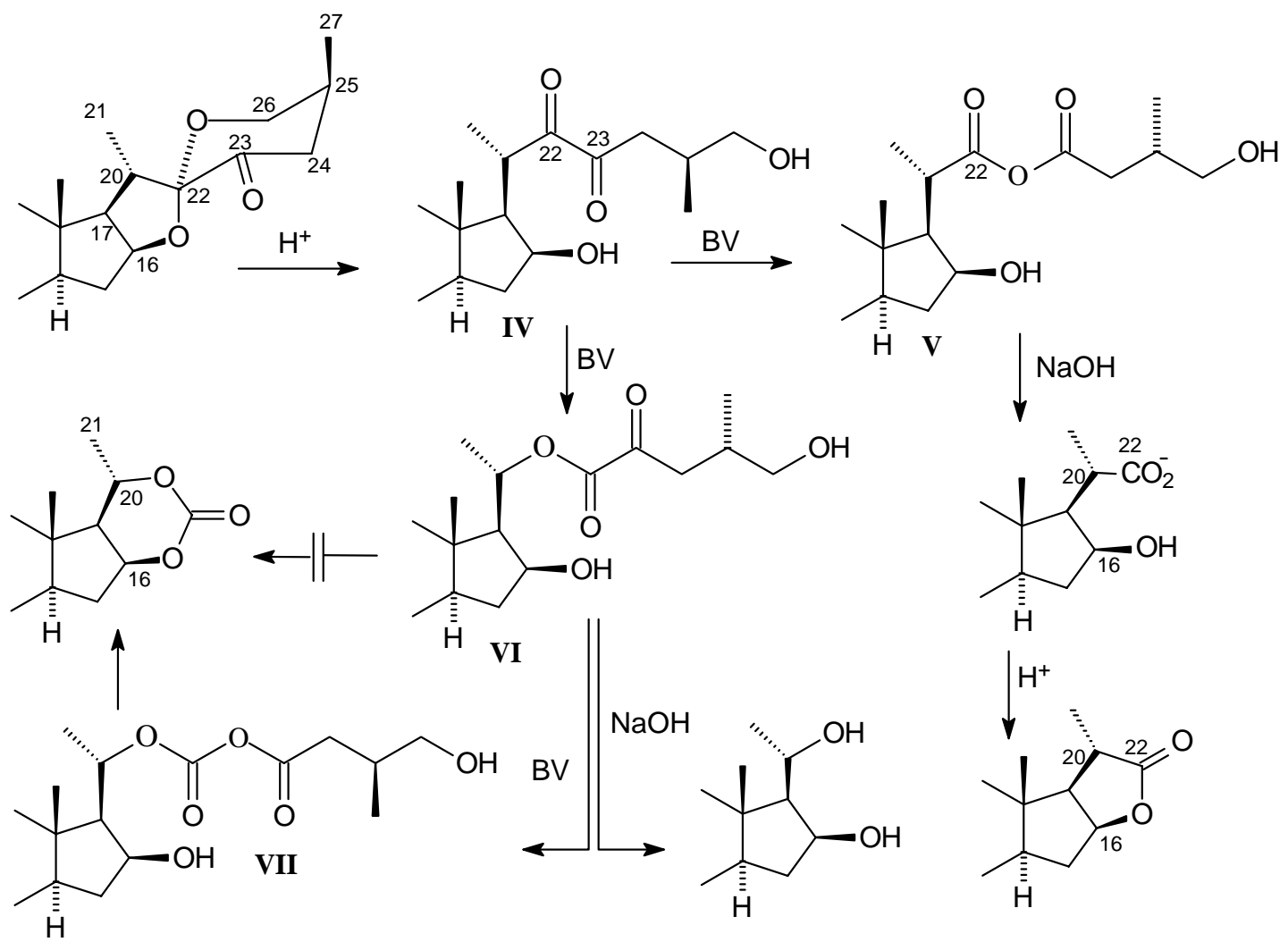

Scheme 4. Marker's open chain mechanism.

\section{Theoretical calculations ${ }^{14}$}

Semiempirical PM3 calculations of the fragments corresponding to 23-oxosapogenins of both $25 R$ and $25 S$ series indicate that neither charges nor LUMO energies can explain the different reactivity observed for the two C-25 epimers. Both reactivity indexes are almost the same for both epimers, therefore the cause of these differences should be other than electronic effects (see Table 3).

Table 3. PM3 obtained LUMO energies and charges at $\mathbf{C}-23$ of ketones $\mathbf{2 a}, \mathbf{2 b}$

\begin{tabular}{lcc}
\hline & Charge at C-23 & Energy of LUMO (eV) \\
\hline 2a (25R) & 0.2673 & 0.59062 \\
2b (25S) & 0.2689 & 0.59074 \\
\hline
\end{tabular}


Figure 6 shows the PM3 optimized geometries of the fragments corresponding to the side chains of both 25R- and 25S-23-oxosapogenins. These optimized geometries are consistent with the previously described NMR data for steroid 25R- and 25S-sapogenins and the coupling pattern of both axial and equatorial $\mathrm{H}-26$ with $\mathrm{H}-25{ }^{11}$

From these results it can be assumed that in the 25S epimer, the $\beta$-side of ring $\mathrm{F}$ is sterically hindered by two methyl groups, as a consequence, axial approach to $\mathrm{C}=\mathrm{O}$ is expected to be highly disfavored. In contrast, equatorial approach to $\mathrm{C}=\mathrm{O}$ (from the $\alpha$-side) seems to be less hindered in both $25 R$ and $25 S$ series as well as axial approach to $\mathrm{C}=\mathrm{O}$ in the $25 R$ epimer (see Figure 6).
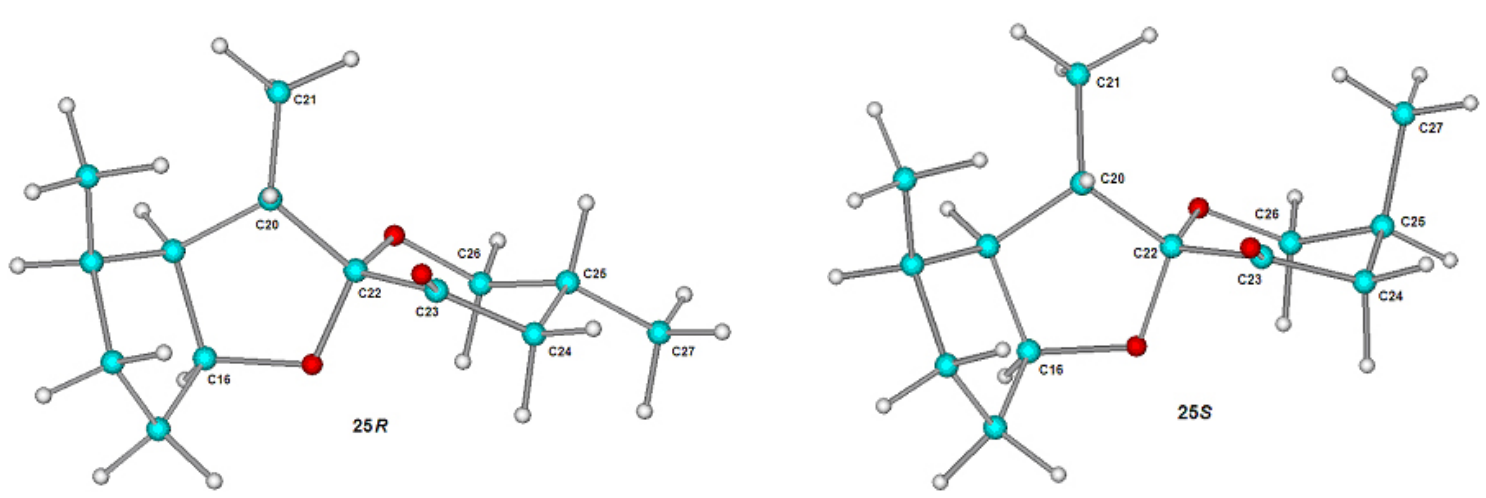

Figure 6. Fragments of the side chains of 25R-and 25S-23-oxosapogenins.

PM3 calculations of the barriers of all possible reaction paths derived from the approach of the peroxyacid to $\mathrm{C}=\mathrm{O}$ from the axial or equatorial directions in both $25 \mathrm{R}$ and $25 \mathrm{~S}$ series, were performed. The results of the reaction barriers calculations as well as the molecular graphics of transition states are shown in Figure 7. The 25R epimer appears to be slightly more reactive to equatorial attack but also axial attack is possible. By contrast, according to the results, the axial approach to the $25 S$ epimer is undoubtedly disfavoured because of the steric hindrance previously mentioned, leaving only one possibility, the equatorial attack, for the production of the Criegee's intermediate. In addition the barrier for equatorial attack in the $25 R$ is $0.6 \mathrm{kcal} / \mathrm{mole}$ lower than this of $25 S$ indicating its higher reactivity. These results plenty justify the experimental evidence that the reaction time in the $25 S$ epimer is twice longer than this of the $25 R$ epimer. 


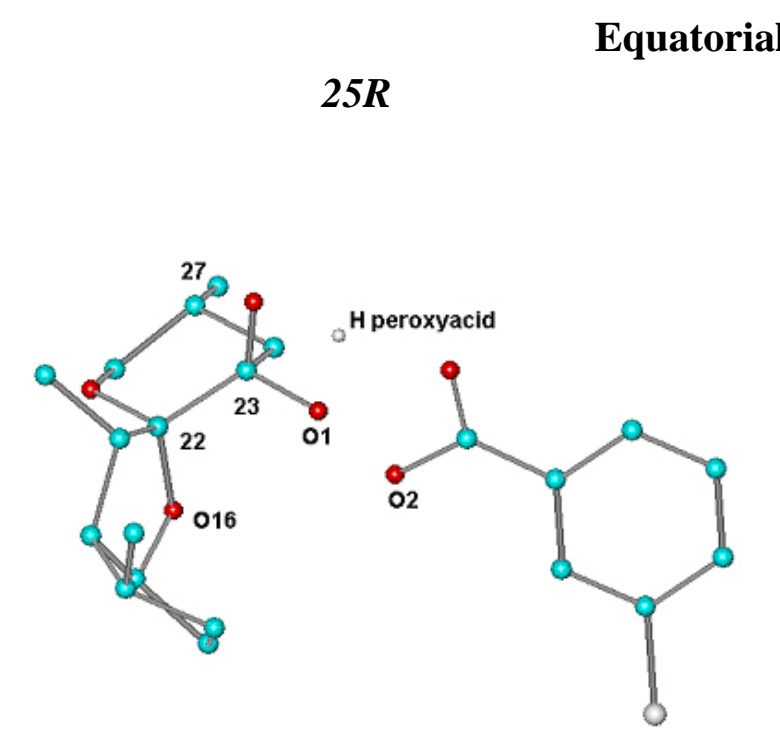

Barrier $\Delta \mathrm{E}=48.35 \mathrm{kcal} / \mathrm{mole}$
$25 S$

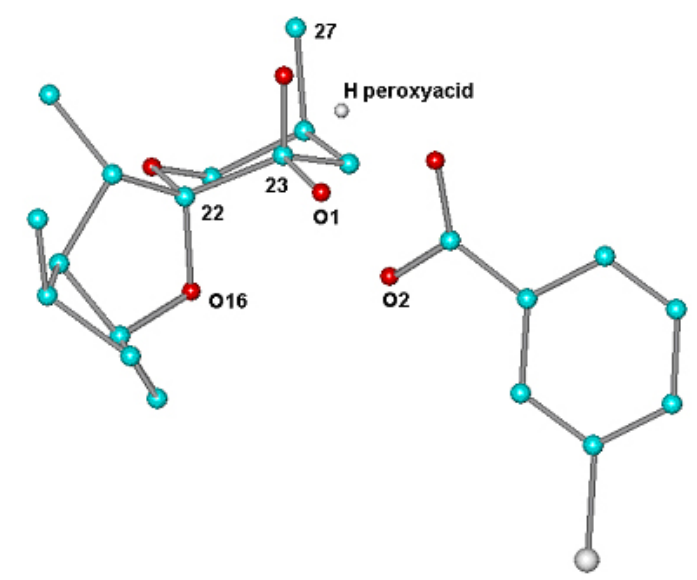

Barrier $\Delta \mathrm{E}=48.98 \mathrm{kcal} / \mathrm{mole}$

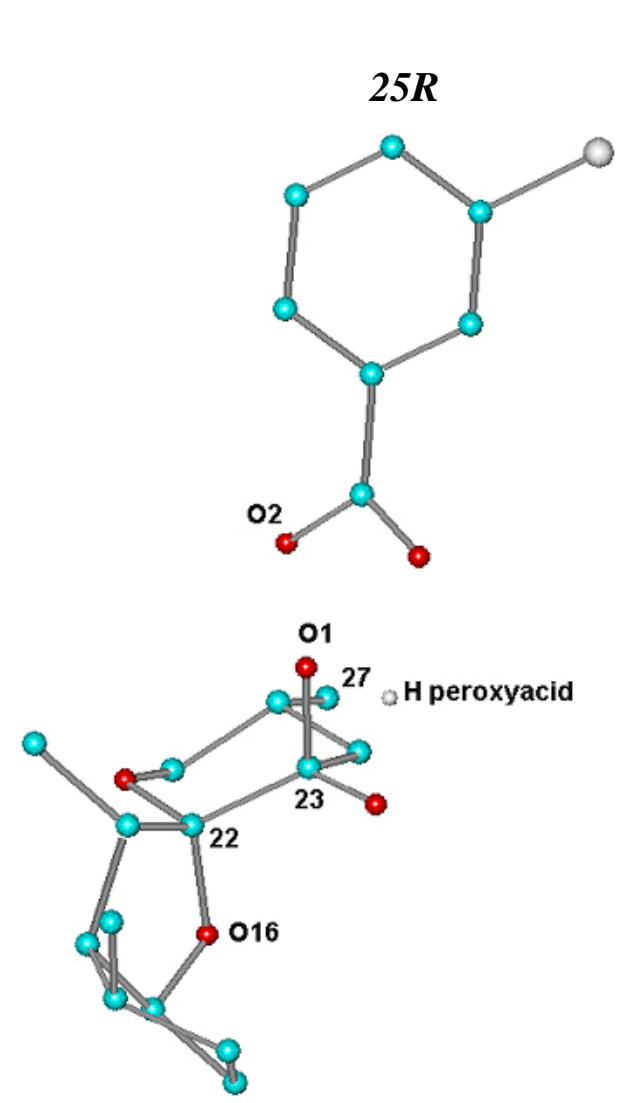

Barrier $\Delta \mathrm{E}=48.68 \mathrm{kcal} / \mathrm{mole}$

\section{Axial approach}

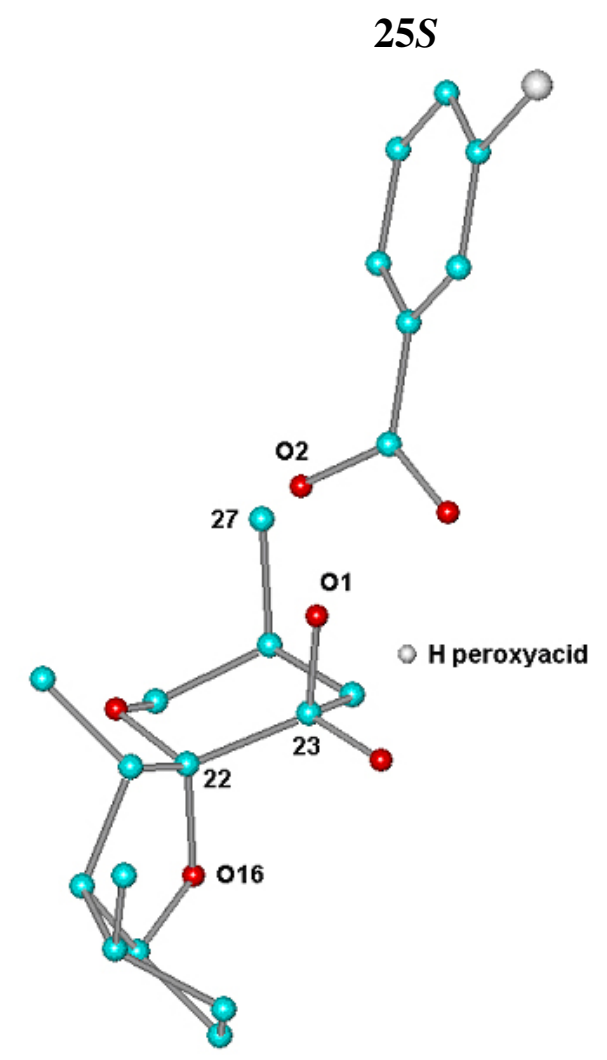

Barrier $\Delta \mathrm{E}=51.20 \mathrm{kcal} / \mathrm{mole}$

Figure 7. Transition states for the addition of the peroxyacid to the C-23 oxo grup. For clarity hydrogens are omitted. 
The regioselective production of bisnorcholanic lactones 3a-c, may be explained in terms of the preference for antiperiplanar migration (App-migration) in the migration step. ${ }^{15}$ This assumption arises from the primary stereoelectronic effect in which orientation of the peroxide bond (O1-O2) should be App to that of the migrating group, in such a way that the $\sigma$ bonding orbital of the migrating group and the $\sigma *$ antibonding orbital of the peroxide bond overlap. ${ }^{16}$

Radkiewicz-Poutsma and coworkers have shown that App-migrations are strongly favored with barriers that can be $58.0 \mathrm{kcal} / \mathrm{mol}$ lower in energy than the gauche migration barriers. Additionally they stated that no transition state could be located for gauche migration. ${ }^{17}$

In this context, the observed regioselectivity can be a consequence of the conformational preference of the Criegee's peroxyester intermediate. PM3 calculations showed that those conformers of the Criegee's intermediate with App arrangement of C22-C23-O1-O2 favorable to the migration of $\mathrm{C}-22$, and hence to produce lactones 3a-c, are preferred over those with App arrangement of C24-C23-O1-O2 favorable to migration of C-24 which would produce the regioisomeric 23-oxo-24-oxa moiety, see Scheme 6 and Figure 8.

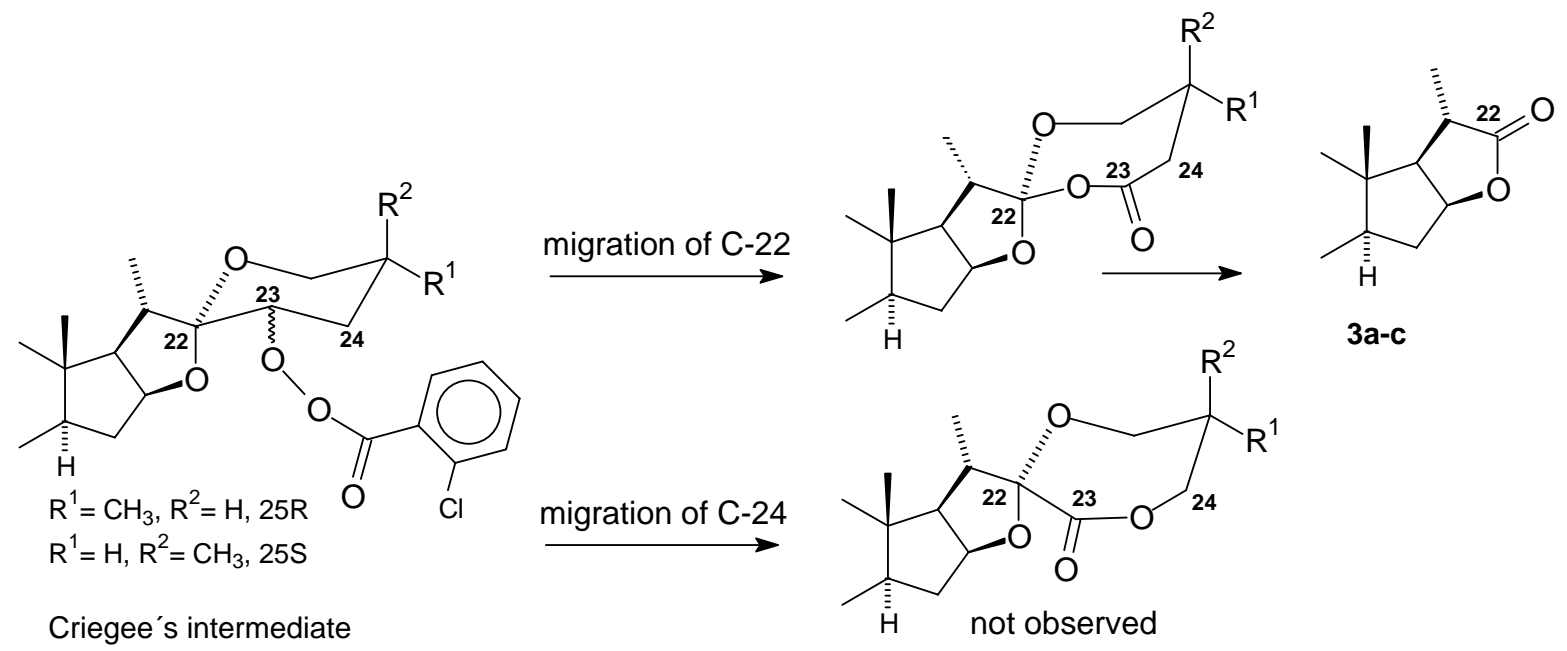

\section{Scheme 6}




\section{Equatorial peroxyester}

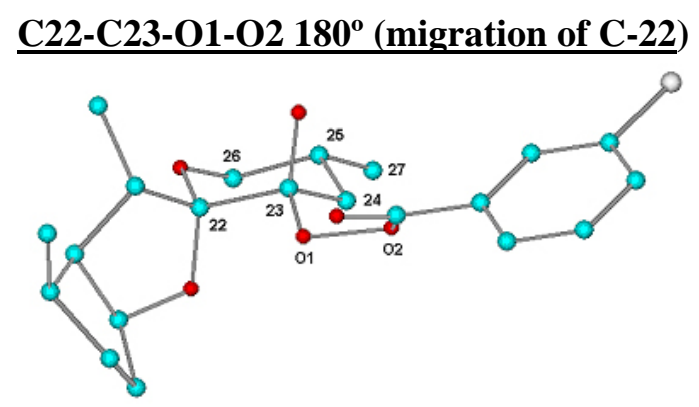

$25 R \Delta H_{\mathrm{f}}=-197.75 \mathrm{kcal} / \mathrm{mole}$

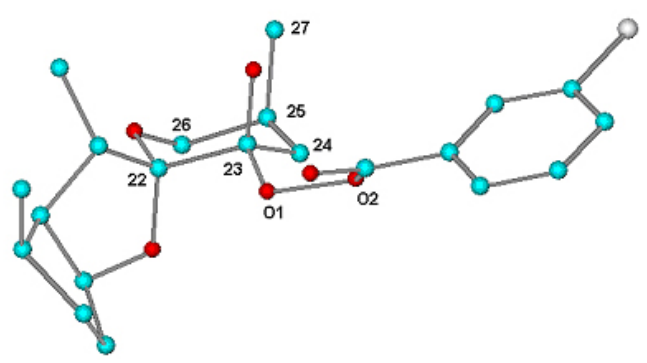

$25 S \Delta \mathrm{H}_{\mathrm{f}}=-196.19 \mathrm{kcal} / \mathrm{mole}$
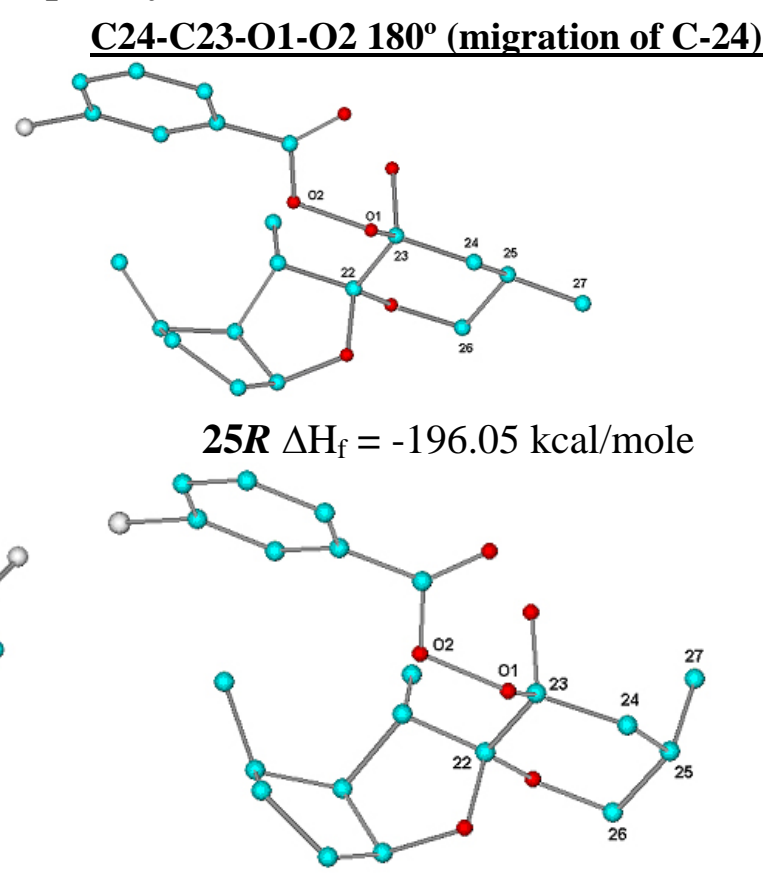

$25 S \Delta \mathrm{H}_{\mathrm{f}}=-194.54 \mathrm{kcal} / \mathrm{mole}$

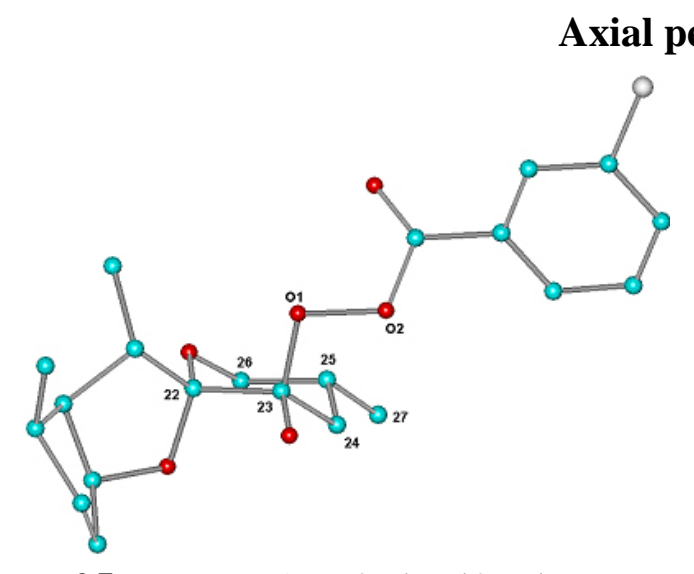

$25 \boldsymbol{R} \Delta \mathrm{H}_{\mathrm{f}}=-197.46 \mathrm{kcal} / \mathrm{mole}$

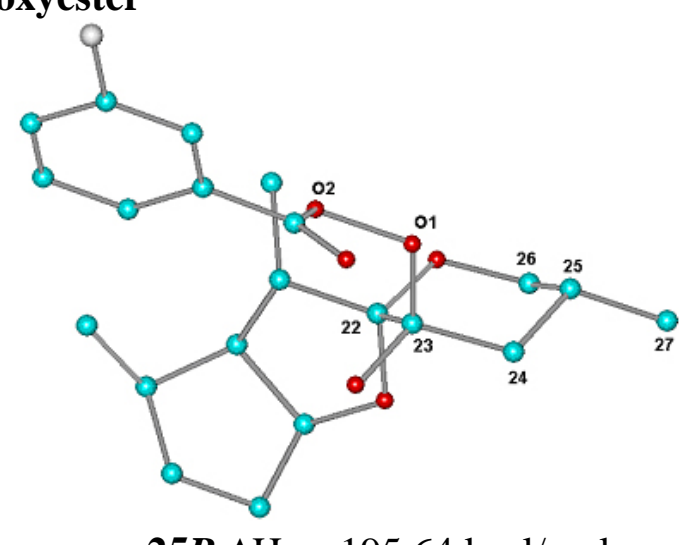

$25 R \Delta \mathrm{H}_{\mathrm{f}}=-195.64 \mathrm{kcal} / \mathrm{mole}$

Figure 8. Conformational preferences for all possible Criegee's intermediates. $\Delta \mathrm{H}_{\mathrm{f}=}$ Calculated heat of formation. For clarity hydrogen atoms are omitted.

\section{Conclusions}

The Baeyer-Villiger reactions of (25R)- and (25S)-23-oxosapogenins produce the cleavage of the spiroketal side chain resulting in a mixture of a bisnorcholanic lactone and a cyclic carbonate of 16,20 diols. This reaction opens a synthetic alternative to bisnorcholanic lactones from the readily available steroid sapogenins. Synthetic applications of these reactions and studies on the effects of acid catalysis are on development. 
The regioselective production of the bisnorcholanic lactones 3a-c may be explained in terms of the preference of those conformers which are favorable to migration of C-22. The reaction follows a course in which the steric factors play a determining role. PM3 calculated reaction barriers accurately reproduce the experimentally observed facts, and therefore its results are confident enough to explain the behavior of this system.

\section{Experimental Section}

General Procedures. Reactions were monitored by TLC on ALUGRAM ${ }^{\circledR}$ SIL G/UV 254 plates from MACHEREY-NAGEL. Chromatographic plates were sprayed with a $1 \%$ solution of vainillin in $50 \% \mathrm{HClO}_{4}$ and heated until color developed. NMR spectra were recorded in on a Varian Unity INOVA $300 \mathrm{MHz}$ spectrometer using TMS for ${ }^{1} \mathrm{H}$ or the solvent signal $\left(\mathrm{CDCl}_{3}\right)$ for ${ }^{13} \mathrm{C}$ as reference. All spectra displayed using the Nuclear Magnetic Resonance data processing software package for desktop computers MestRe-C. ${ }^{18}$ Mass spectra were recorded on a Jeol SX-102-A spectrometer. Melting points were measured on a Melt-Temp II equipment and are uncorrected.

(25R)-5 $\beta$-Spirostan-3 $\alpha$-ol acetate, 3-epismilagenin acetate (1a). m.p. 159-160 ${ }^{\circ}$ C, Lit. $^{19} 162-$ $164{ }^{\circ} \mathrm{C} .{ }^{1} \mathbf{H}$ NMR (300 MHz, $\mathrm{CDCl}_{3}$ ): 4.70 (m, 1H, H-3); 4.38 (m, 1H, H-16); 3.47 (dd J 4 Hz 10.6 Hz, 1H, H-26 eq.); 3.36 (t J 10.8 Hz, 1H, H-26 ax.); 2.01 (s, 3H, $\mathrm{CH}_{3}$ acetyl); 0.95 (d J 7.0 Hz, 3H, Me-21); 0.93 (s, 3H, H-19); 0.77 (d J 6.3Hz, 3H, H-27); 0.74 (s, 3H, H-18) ${ }^{13}$ C NMR (75.5 MHz, $\mathrm{CDCl}_{3}$ ): C-1 31.0; C-2 26.5; C-3 74.3; C-4 32.2; C-5 41.6; C-6 26.9; C-7 26.5; C-8 35.4; C-9 40.5; C-10 34.7; C-11 20.6; C-12 40.2; C-13 40.6; C-14 56.3; C-15 31.7; C-16 80.8; C-17 62.2; C-18 16.4; C-19 23.3; C-20 41.7; C-21 14.5; C-22 109.2; C-23 31.3; C-24 28.7; C-25 30.3; C-26 66.8; C-27 17.1; $\mathrm{CH}_{3}$ acetyl 21.4, C=O acetyl 170.6.

(25S)-5 $\beta$-Spirostan-3 $\beta$-ol acetate, sarsasapogenin acetate (1b). m.p. $143-144^{\circ} \mathrm{C}, \mathrm{Lit}^{20} 145^{\circ} \mathrm{C}$. ${ }^{1} \mathbf{H}$ NMR (300 MHz, CDCl $)$ ): 5.05 (m, 1H, H-3); 4.39 (dd J 7.5 Hz, J 13.9 Hz, 1H, H-16); 3.94 (dd J 2.5 Hz J 10.9 Hz, 1H, H-26 ax.); 3.29 (d J 10.9 Hz, 1H, H-26 eq.); 2.03 (s, 3H, $\mathrm{CH}_{3}$ acetyl); 1.82 (m 1H, H-20); 1.06 (d J 7.1 Hz, 3H, H-21); 0.98 (d J 5.2 Hz, 3H, H-27); 0.97 (s, 3H, H-19); 0.75 (s, 3H, H-18). ${ }^{13}$ C NMR (75.5 MHz, CDCl 3 ): C-1 30.6; C-2 25.0; C-3 70.7; C-4 30.7; C-5 37.3; C-6 26.4; C-7 26.4; C-8 35.3; C-9 40.0; C-10 35.0; C-11 20.9; C-12 40.2; C-13 40.6; C-14 56.3; C-15 31.7; C-16 81.0; C-17 62.1; C-18 16.0; C-19 23.8; C-20 42.1; C-21 14.3; C-22 109.7; C-23 25.9; C-24 25.7; C-25 27.1; C-26 65.1; C-27 16.0; $\mathrm{CH}_{3}$ acetyl 21.5, C=O acetyl 170.7.

(25R)-5 $\alpha$-Spirostan-3 $\beta, 12 \beta$-diol diacetate, rockogenin acetate (1c). Yield $65.3 \%$ Identical as described in ref. 10. ${ }^{1} \mathbf{H}$ NMR (300 MHz, $\mathrm{CDCl}_{3}$ ): 4.65 (m, 1H, H-3); 4.51 (dd, J 4.7 Hz J 11.2 Hz, 1H, H-12); 4.37 (dd J 7.5Hz J 14.6 Hz, 1H, H-16); 3.43 (dd J 2.9 Hz J 10.7 Hz, 1H, H-26 eq.); 3.32 (dd J $10.9 \mathrm{~Hz}, \mathrm{~J} 10.9 \mathrm{~Hz}, 1 \mathrm{H}, \mathrm{H}-26$ ax.); 2.01 (s, 3H, $\mathrm{CH}_{3}$ acetyl); 1.99 (s, 3H, $\mathrm{CH}_{3}$ acetyl); 0.90 (d J 6.6 Hz, 3H, H-21); 0.85 (s, 3H, H-19); 0.84 (s, 3H, H-18); 0.78 (d J 6.3 Hz, H27). ${ }^{13}$ C NMR (75.5 MHz, $\mathrm{CDCl}_{3}$ ): C-1 36.5; C-2 27.2; C-3 73.3; C-4 33.8; C-5 44.4; C-6 28.3; C-7 31.1; C-8 34.0; C-9 52.6; C-10 35.5; C-11 26.7; C-12 81.6; C-13 44.5; C-14 54.7; C-15 
31.6; C-16 80.4; C-17 61.2; C-18 11.5; C-19 12.1; C-20 42.1; C-21 13.6; C-22 109.2; C-23 31.3; C-24 28.7; C-25 30.2; C-26 66.8; C-27 17.1; $\mathrm{CH}_{3}$ acetyl 21.5, 21.4; C=O acetyl 170.5, 170.4.

\section{General procedure to obtain 23-oxosapogenins}

$\mathrm{BF}_{3} . \mathrm{Et}_{2} \mathrm{O}(0.8 \mathrm{~mL})$ was slowly added to a well stirred solution of the steroid sapogenin acetate $(1 \mathrm{mmol})$ in glacial acetic acid $(20 \mathrm{~mL})$, the mixture was stirred for $5 \mathrm{~min}$ followed by addition of $\mathrm{NaNO}_{2}$ (200 mg, $2.9 \mathrm{mmol}$ ) in small portions over a period of one hour. The mixture was stirred for one additional hour, poured into ice/water and extracted with $\mathrm{CH}_{2} \mathrm{Cl}_{2}$ (2x $30 \mathrm{~mL}$ ); the organic layer was washed with water (2x20 mL), 5\% $\mathrm{NaHCO}_{3}(2 \times 15 \mathrm{~mL})$ and brine $(3 \times 20 \mathrm{~mL})$, dried $\left(\mathrm{Na}_{2} \mathrm{SO}_{4}\right)$ and evaporated. The syrupy product dissolved in benzene-hexane $(3 / 2,8 \mathrm{~mL})$ was allowed to stand overnight in a column packed with neutral $\mathrm{Al}_{2} \mathrm{O}_{3}$ (15 g, Brockmann III). Slow elution with hexane/ethyl acetate (8/1 for $\mathbf{2 a}$ and $\mathbf{2 b}, \mathbf{4} / \mathbf{1}$ for $\mathbf{2}$ ) afforded the desired 23oxosapogenin acetate. Further elution with 1/1 hexane/ethyl acetate afforded an small amount of the corresponding bisnorcholanic lactone, (see Table 4 for yields).

Table 4. Synthesis of 23-oxosapogenins

\begin{tabular}{cc}
\hline Starting material & Products (yield \%) \\
\hline 1a & 2a (63), 3a (10) \\
1b & 2b (58), 3b (16) \\
1c & 2c (65), 3c (12) \\
\hline
\end{tabular}

(25R)-3 $\alpha$-Acetoxy-5 $\beta$-spirostan-23-one, 23-oxo-3-epismilagenin acetate (2a). m.p. 155$157^{\circ} \mathrm{C}^{1}{ }^{1} \mathbf{H}$ NMR (300 MHz, CDCl3): 4.70 (tt J 4.7Hz, J 11.3Hz, 1H, H-3 ); 4.59 (m, 1H, H-16); 3.77 (dd, J 11.2 Hz, 11.2 Hz, 1H, H-26 ax.); 3.57 (dd, J 4.2 Hz J 11.2 Hz, 1H, H-26 eq.); 2.86 (q J 7.0Hz, 1H, H-20); 2.27 (m, 1H, H-25); 2.01 (s, 3H, $\mathrm{CH}_{3}$ acetyl); 0.93 (s, 3H, H-19); 0.92 (d J $6.4 \mathrm{~Hz}, 3 \mathrm{H}, \mathrm{H}-27) ; 0.93$ (d J $6.6 \mathrm{~Hz}, 3 \mathrm{H}, \mathrm{H}-21) ; 0.74$ (s, 3H, H-18). ${ }^{13} \mathrm{C}$ NMR (75.5 MHz, $\mathrm{CDCl}_{3}$ ): C-1 35.0; C-2 26.5; C-3 74.2; C-4 32.2; C-5 41.6; C-6 26.9; C-7 26.6; C-8 35.4; C-9 40.5; C-10 34.7; C-11 20.5; C-12 39.9; C-13 41.1; C-14 56.4; C-15 31.7; C-16 83.4; C-17 61.8; C-18 16.1; C-19 23.3; C-20 34.7; C-21 14.3; C-22 109.8; C-23 201.8; C-24 45.2; C-25 35.8; C26 65.6; C-27 17.0; $\mathrm{CH}_{3}$ acetyl 21.4, $\mathrm{C}=\mathrm{O}$ acetyl 170.5. $\mathrm{MS}(70 \mathrm{eV}): 472 \mathrm{M}^{+}, 444\left(\mathrm{M}^{+}-\mathrm{C}=\mathrm{O}\right)$, 389, 329, 315, 255, 147, 93, 56, 43. HRMS FAB observed $473.3263 \mathrm{MH}^{+}$; estimated for $\mathrm{C}_{29} \mathrm{H}_{45} \mathrm{O}_{5} 473.3267$.

(25S)-3 $\beta$-Acetoxy-5 $\beta$-spirostan-23-one 23-oxosarsasapogenin acetate, (2b). m.p. $168-170^{\circ} \mathrm{C}$, Lit. ${ }^{13}$ 172-173 ${ }^{\circ}$ C. ${ }^{1} \mathbf{H}-\mathbf{N M R}\left(300 \mathrm{MHz}, \mathrm{CDCl}_{3}\right.$ ): 5.05 (m, 1H, H-3); 4.60 (dt J $6.2 \mathrm{~Hz} \mathrm{~J} \mathrm{7.7} \mathrm{Hz,}$ 1H, H-16); 4.26 (dd J 2.8 Hz J 11.2 Hz, 1H, H-26 ax.); 3.40 (td J 2.0 Hz J 11.1 Hz, 1H, H-26 eq.); 2.88 (m, 1H, H-20); 2.03 (s, 3H, $\mathrm{CH}_{3}$ acetyl); 1.06 (d J 7.0 Hz 3H, H-21 ); 0.97 (s, 3H, H19); 0.94 (d J 7.0 Hz, 1H, H-27) 0.76 (s, 3H, H-18). ${ }^{13}$ C NMR (75.5 MHz, CDCl $)$ ): C-1 30.6; C2 25.0; C-3 70.6; C-4 30.7; C-5 37.3; C-6 26.4; C-7 26.4; C-8 35.2; C-9 40.0; C-10 35.0; C-11 20.8; C-12 40.0; C-13 41.2; C-14 56.5; C-15 31.7; C-16 83.5; C-17 61.8; C-18 16.2; C-19 23.8; C-20 35.1; C-21 14.2; C-22 110.7; C-23 202.3; C-24 43.9; C-25 33.7; C-26 64.5; C-27 17.7; $\mathrm{CH}_{3}$ 
acetyl 21.5, C=O acetyl 170.7. MS (70 eV): $472 \mathrm{M}^{+}, 444 \mathrm{M}^{+}-\mathrm{C}=\mathrm{O}, 389,329,315,255,147,93$, $56,43$.

(25R)-3 $\beta, 12 \beta$-Diacetoxy-5 $\alpha$-spirostan-23-one, 23-oxorockogenin acetate (2c). Identical as described in ref. 10. ${ }^{1}$ H-NMR (300 MHz, $\mathrm{CDCl}_{3}$ ): 4.67 (m, 2H, H-3, H-16); 4.54 (dd J 4.6 Hz J 11.0 Hz, 1H, H-12); 3.76 (dd J 11.2 Hz, 1H, H-26 ax.); 3.58 (dd J 4.1 Hz J 11.2 Hz, 1H, H-26

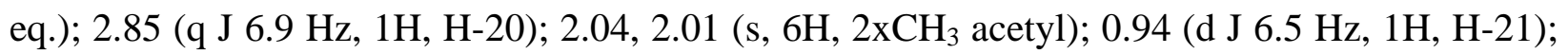
0.86 (s, 3H, H-19); 0.84 (s, 3H, H-18); 0.86 (d J 7 Hz, 3H, H-27). ${ }^{13}$ C NMR (75.5 MHz, CDCl $)$ : C-1 36.5; C-2 27.2; C-3 73.3; C-4 33.8; C-5 44.5; C-6 28.3; C-7 31.1; C-8 34.0; C-9 52.6; C-10 35.6; C-11 26.7; C-12 81.3; C-13 45.0; C-14 54.8; C-15 31.6; C-16 82.9; C-17 60.7; C-18 11.4; C-19 12.1; C-20 35.7; C-21 13.5; C-22 109.8; C-23 201.7; C-24 45.2; C-25 35.3; C-26 65.6; C27 17.0; $\mathrm{CH}_{3}$ acetyl 21.5, 21.4; $\mathrm{C}=\mathrm{O}$ acetyl 170.6, 170.5. $\mathrm{MS}(70 \mathrm{eV}): 531 \mathrm{MH}^{+}, 502 \mathrm{M}^{+}-\mathrm{C}=\mathrm{O}$, 447, 388, 327, 253, 215, 146, 102, 56, 49.

3 $\alpha$-Acetoxy-16-hydroxy-5 $\beta$-bisnorcholanic acid-(22 $\rightarrow$ 16) lactone (3a). m.p. 153-155 $\mathrm{C}$, Lit. $^{21} 158{ }^{\circ} \mathrm{C} .{ }^{1} \mathbf{H}$ NMR (300 MHz, CDCl3): 4.95 (ddd J 4.6 Hz J 7.8 Hz J 7.8 Hz, 1H, H-16); 4.73 (dddd J 4.8 Hz J 4.8 Hz J 11.3 Hz J 11.3 Hz, 1H, H-3); 2.58 (dq J 1.1 Hz, J 7.6 Hz, 1H, H-

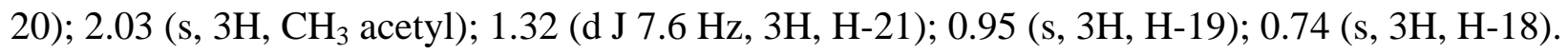
${ }^{13}$ C NMR (75.5 MHz, CDCl $)$ : C-1 34.9; C-2 26.5; C-3 74.1; C-4 32.1; C-5 41.6; C-6 26.7; C-7 26.5; C-8 35.4; C-9 40.6; C-10 34.6; C-11 20.1; C-12 38.4; C-13 41.8; C-14 54.6; C-15 33.0; C16 82.7; C-17 59.1; C-18 13.8; C-19 23.2; C-20 36.0; C-21 17.9; C-22 181.2. $\mathrm{CH}_{3}$ acetyl 21.4, $\mathrm{C}=\mathrm{O}$ acetyl 170.5. $\mathrm{MS}(70 \mathrm{eV}): 389 \mathrm{MH}^{+}, 328 \mathrm{M}^{+}-\mathrm{CH}_{3} \mathrm{COOH}, 313,274,215,161,93,79,43$.

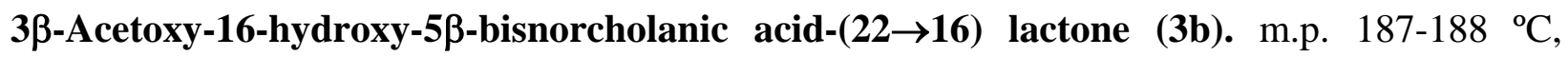
Lit. $^{22}$ 184.5-185.5 ${ }^{\circ} \mathrm{C} .{ }^{1} \mathrm{H}-\mathrm{NMR}\left(300 \mathrm{MHz}, \mathrm{CDCl}_{3}\right.$ ): 5.05 (m, 1H, H-3); 4.92 (dt J 4.6Hz J 7.7Hz, 1H, H-16); 2.56 (q J 7.6Hz, 1H, H-20); 2.03 (s, 3H, $\mathrm{CH}_{3}$ acetyl); 1.30 (d J 7.6 Hz, 3H, H-21); 0.97 (s, 3H, H-19); 0.72 (s, 3H, H-18). ${ }^{13}$ C NMR (75.5 MHz, CDCl $)$ ): C-1 30.5; C-2 25.0; C-3 70.4; C-4 30.7; C-5 37.1; C-6 26.3; C-7 26.2; C-8 35.0; C-9 40.1; C-10 34.9; C-11 20.3; C-12 38.5; C-13 41.8; C-14 54.6; C-15 33.0; C-16 82.8; C-17 59.1; C-18 13.8; C-19 23.7; C-20 36.2; C-21 17.9; C-22 181.4; $\mathrm{CH}_{3}$ acetyl 21.4, $\mathrm{C}=\mathrm{O}$ acetyl 170.6. $\mathrm{MS}(70 \mathrm{eV}): 389, \mathrm{MH}^{+}, 328, \mathrm{M}^{+}-$ $\mathrm{CH}_{3} \mathrm{COOH}, 315,274,215,161,107,93,43$.

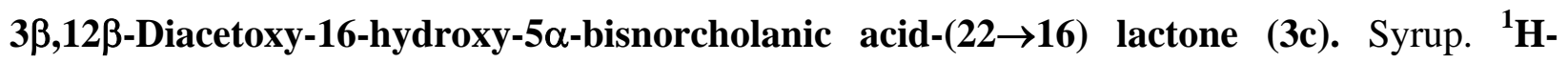
NMR (300 MHz, $\mathrm{CDCl}_{3}$ ): 4.91 (dt J 4.7Hz J 7.8Hz, 1H, H-16); 4.64 (m, 2H, H-3 and H-12); 2.50 (m, 1H, H-20); 2.03 (s, 3H, $\mathrm{CH}_{3}$ acetyl); 2.00 (s, 3H, $\mathrm{CH}_{3}$ acetyl); 1.24 (d J 7.7Hz, 3H, H21); 0.83 (s, 3H, H-19); 0.82 (s, 3H, H-18). ${ }^{13}$ C NMR (75.5 MHz, CDCl 3 ): C-1 36.5; C-2 27.2; C-3 73.2; C-4 33.7; C-5 44.4; C-6 28.7; C-7 31.5; C-8 33.8; C-9 52.7; C-10 35.5; C-11 26.5; C12 80.3; C-13 45.6; C-14 52.6; C-15 32.5; C-16 82.1; C-17 57.6; C-18 9.4; C-19 12.0; C-20 37.1; C-21 17.3; C-22 181.0; $\mathrm{CH}_{3}$ acetyl 21.4, 21.1; C=O acetyl 170.6, 170.4. MS (70 eV): 447 $\mathrm{MH}^{+}, 386 \mathrm{M}^{+}-\mathrm{CH}_{3} \mathrm{COOH}, 326 \mathrm{M}^{+}-2 \mathrm{xCH}_{3} \mathrm{COOH}, 272,253,213,161,108,43$. HRMS FAB observed $447.2743 \mathrm{MH}^{+}$; estimated for $\mathrm{C}_{26} \mathrm{H}_{39} \mathrm{O}_{6} 447.2747$

\section{Baeyer-Villiger reaction, general procedure}

MCPBA ( $80 \%$ activity) (690 mg, $4 \mathrm{mmol}$ ) was added to a solution of the 23-oxosapogenin 
(1 mmol) in $\mathrm{CH}_{2} \mathrm{Cl}_{2}$ (25 mL) and the mixture was stirred, (see Table 3 for reaction times). The mixture without workup ${ }^{23}$ was poured into a chromatographic column packed with silica gel (25 g) and eluted with hexane/ethyl acetate mixture (10/0 to 1/1). Evaporation of the adequate fractions afforded (in this order), the bisnorcholanic lactone (identical as described above) and the more polar carbonate, (see Table 5 for yields).

Table 5. Results of the BV reactions of 23-oxosapogenins

\begin{tabular}{|c|c|c|}
\hline Starting material & Products (yield \%) & Reaction time \\
\hline $2 a$ & 3a (63), 4a (26) & 29 days \\
\hline $2 \mathbf{b}$ & 3b (69), $4 \mathbf{b}$ (19) & 66 days \\
\hline $2 c$ & $3 c(54), 4 c(24)$ & 26 days \\
\hline
\end{tabular}

(20S)-3 $\alpha$-Acetoxy-16 $\beta, 20$-dihydroxy-5 $\beta$-pregnan-16,20 carbonate (4a). m.p. 148-150 C (descomp.). ${ }^{1} \mathbf{H}-\mathbf{N M R}$ (300 MHz, CDCl3): 4.73 (m, 2H, H-3 and H-16); 4.43 (m, 1H, H-20); 2.02 (s, 3H, $\mathrm{CH}_{3}$ acetyl); 1.45 (d J 6.4Hz, 3H, H-21); 0.94 (s, 3H, H-19); 0.86 (s, 3H, H-18) ${ }^{13} \mathrm{C}$

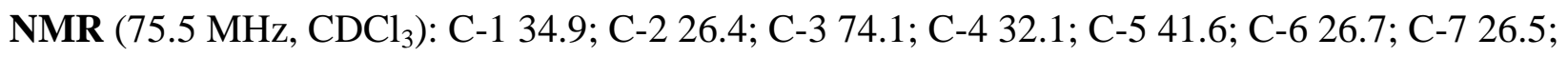
C-8 34.6; C-9 40.5; C-10 34.6; C-11 20.1; C-12 38.7; C-13 41.9; C-14 53.2; C-15 33.2; C-16 80.3; C-17 55.4; C-18 14.9; C-19 23.2; C-20 74.6; C-21 21.4; C=O carbonate 152.0; $\mathrm{CH}_{3}$ acetyl 21.8, $\mathrm{C}=\mathrm{O}$ acetyl 170.6. MS (70 eV): $405 \mathrm{MH}^{+}, 344 \mathrm{M}^{+}-\mathrm{CH}_{3} \mathrm{COOH}, 329,290,267,215,174$, 147, 108. HRMS FAB observed 405.2635 $\mathrm{MH}^{+}$; estimated for $\mathrm{C}_{24} \mathrm{H}_{37} \mathrm{O}_{5} 405.2641$.

(20S)-3 $\beta$-Acetoxy-16 $\beta, 20$-dihydroxy-5 $\beta$-pregnan-16,20 carbonate (4b). m.p. 212-214 $\mathrm{C}$ (descomp.). ${ }^{1} \mathbf{H}-\mathrm{NMR}$ (300 MHz, $\mathrm{CDCl}_{3}$ ): 5.07 (m, 1H); 4.77 (dt J= 5.7Hz, J=8.2Hz, 1H H-16);

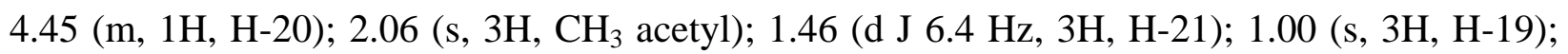
0.88 (s, 3H, H-18). ${ }^{13} \mathrm{C}$ NMR (75.5 MHz, $\mathrm{CDCl}_{3}$ ): C-1 30.5; C-2 24.9; C-3 70.5; C-4 30.6; C-5 37.1; C-6 26.2; C-7 26.1; C-8 34.5; C-9 40.0; C-10 34.9; C-11 20.3; C-12 38.7; C-13 41.9; C-14 53.2; C-15 33.2; C-16 80.3; C-17 55.3; C-18 14.9; C-19 23.7; C-20 74.6; C-21 21.5; C=O carbonate 152.0; $\mathrm{CH}_{3}$ acetyl 21.8, $\mathrm{C}=\mathrm{O}$ acetyl 170.6. MS (70 eV): $405 \mathrm{MH}^{+}, 344 \mathrm{M}^{+}$$\mathrm{CH}_{3} \mathrm{COOH}, 329,290,267,241,175,147,108,93$, 43. HRMS FAB observed $405.2644 \mathrm{MH}^{+}$; estimated for $\mathrm{C}_{24} \mathrm{H}_{37} \mathrm{O}_{5} 405.2641$.

(20S)-3 $\beta, 12 \beta$-Diacetoxy-16 $\beta, 20$-dihydroxy-5 $\alpha$-pregnan-16,20 carbonate (4c). m.p. 167-169 C (descomp.). ${ }^{1} \mathrm{H}-\mathrm{NMR}$ (300 MHz, $\mathrm{CDCl}_{3}$ ): 4.83 (dt J $5.2 \mathrm{~Hz}$ J $8.1 \mathrm{~Hz}, 1 \mathrm{H}, \mathrm{H}-16$ ); 4.66 (m, 1H, H-3); 4.58 (dd J 4.8 Hz J 11.1 Hz, 1H, H-12); 4.47 (m, 1H, H-20); 2.04 (s, 3H, CH 3 acetyl); 2.00 (s, 3H, $\mathrm{CH}_{3}$ acetyl); 1.42 (d J $6.5 \mathrm{~Hz}, 3 \mathrm{H}, \mathrm{H}-21$ ); 0.98 (s, 3H, H-18); 0.84 (s, 3H, H-19). ${ }^{13} \mathrm{C}$ NMR (75.5 MHz, CDCl 3 ): C-1 36.5; C-2 27.2; C-3 73.2; C-4 33.7; C-5 44.4; C-6 28.1; C-7 31.3; C-8 33.4; C-9 52.5; C-10 35.5; C-11 26.6; C-12 80.5; C-13 45.7; C-14 53.7; C-15 33.1; C-16 79.6; C-17 51.5; C-18 10.3; C-19 12.0; C-20 75.1; C-21 21.7; C=O carbonate 150.7; $\mathrm{CH}_{3}$ acetyl 21.4, 21.3; $\mathrm{C}=\mathrm{O}$ acetyl 170.7, 170.4. MS (70 eV): $463 \mathrm{MH}^{+}, 402 \mathrm{M}^{+}-\mathrm{CH}_{3} \mathrm{COOH}, 342 \mathrm{M}^{+}-$ $2 \mathrm{xCH}_{3} \mathrm{COOH}, 327,288,280,226,213,159,147,107,93$. HRMS FAB observed 463.2692 $\mathrm{MH}^{+}$; estimated for $\mathrm{C}_{26} \mathrm{H}_{39} \mathrm{O}_{7} 463.2696$. 


\section{Acknowledgements}

We thank Dirección General de Asuntos del Personal Académico (DGAPA-UNAM) for financial support via project IN200105 and Professor Benjamin Ruiz Loyola (UNAM) for facilities provided at Laboratory 4D. We are also indebted to Victor M. Arroyo Sánchez and Margarita Guzmán Villanueva (USAI-UNAM) for registering NMR and Mass spectra.

\section{References and notes}

1. (a) Rosenkranz , G.; Mancera O.; Sondheimer, F.; Djerassi, C. J. Org. Chem. 1956, 21, 520. (b) Ringold, H. J.; Rosenkranz, G.; Sondheimer, F. J. Am. Chem. Soc. 1956, 78, 820. (c) Rosenkranz, G.; Pataki, J.; Djerassi, C. J. Am. Chem. Soc. 1951, 73, 4055. (d) Lee, E.; Liu, Y-T.; Solomon, P. H.; Nakanishi, K. J. Am. Chem. Soc. 1976, 98, 1634.

2. Lee, E.; Liu, Y-T.; Solomon, P. H.; Nakanishi, K. J. Am. Chem. Soc. 1976, 98, 1634.

3. (a) Iglesias-Arteaga M.A.; Pérez, R.; Leliebre V.; Pérez, C.S.; Coll F. J. Chem. Res. (S) 1996, 504. (b) Iglesias-Arteaga M.A.; Leliebre V.; Pérez, C.S.; Coll F. Quim. Nova 1997, 20, 361.; Chem. Abstr. 1997; 127, 95449. (c) Iglesias-Arteaga, M.A.; Pérez, R.; Leliebre, V.; Pérez, C. S.; Rosado, A.; Coll, F. Synth. Commun. 1998, 28, 1381. (d) Iglesias-Arteaga M.A.; Pérez, R.; Leliebre, V.; Pérez, C.S.; Coll F. Synth. Commun. 1998; 28, 1779. (e) Iglesias-Arteaga, M. A.; Pérez, R.; Pérez, C. S.; Coll, F. J. Chem. Soc., Perkin Trans. 1 2001, 261. (f) Iglesias-Arteaga, M. A.; Pérez, R.; Pérez, C. S.; Coll, F. Steroids. 2002, 67, 159.

4. Fieser, L.; Fieser, M. Steroids, Reinhold: San Francisco, 1959, and references therein.

5. (a) Hernández, R.; Marrero-Tellado, J. J.; Prout, K.; Suárez, E. J. Chem. Soc., Chem. Commun. 1992, 275. (b) Sandoval-Ramirez, J.; Castro-Mendez, A.; Meza-Reyes, S.; ReyesVázquez, S.; Santillán, R.; Farfán, N. Tetrahedron Lett. 1999, 40, 5143. (c) LaCour, T. G.; Tong, Z.; Fuchs, P. L. Org. Lett. 1999, 1, 1815. (d) Betancour C.; Dorta R. L.; Freire R.; Martin A.; Prange, T.; Suárez, E. J. Org. Chem. 2002, 67, 6355. (e) Sandoval-Ramírez, J.; Meza-Reyes, S.; del Río, R. E.; Hernandez-Linares, G; Suárez-Rojas, A.; Rincón, S.; Farfán, N.; Santillán, R. L. Steroids 2003, 68, 199. (f) Cyranski, M. K.; Frelek, J.; Jastrzebska, I.; Morzycki, J. W. Steroids 2004, 69, 395.

6. (a) Morzycki, J. W.; Jastrzebska, I. Tetrahedron Lett. 2001, 42, 5989. (b) AnulewiczOstrowska, R.; Morzycki, J. W.; Jastrzebska, I.; Wojcik, J. J. Org. Chem. 2002, 67, 6916. (c) Iglesias-Arteaga, M. A.; Sandoval-Ramírez, J.; Mata-Esma, M. Y.; Viñas-Bravo, O.; Bernès, S. Tetrahedron Lett. 2004, 45, 4921. (d) Jastrzebska, I.; Morzycki, J. W.; Trochimowicz, U. Tetrahedron Lett. 2004, 45, 1929.

7. (a) González, A. G.; Darias, V.; Suarez, M. C.; Janssen, K. Il Farmaco Ed. Sci. 1983, 38, 3. (b) Mola Garate, J. L.; Suárez García, L.; Pérez Martinez, C. S; Iglesias-Arteaga, M. A.; Coll Herrera, D.; Coll Manchado, F. Synth. Commun. 2003, 33, 1203. 
8. (a) Corcoran, J. W.; Hirschmann, H. J. Am. Chem. Soc. 1956, 78, 2325. (b) Anagnostopoulos, C. E.; Fieser, L. F. J. Am. Chem. Soc. 1954, 76, 532. (c) Barton, D. H. R.; Sammes, P. G.; Taylor, M. V.;Werstiuk, E. J. Chem. Soc. (C) 1970, 1977.

9. (a) Sato, Y.; Ikekawa, N. J. Org. Chem. 1960, 25, 786. (b) Sato, Y.; Ikekawa, N. J. Org. Chem. 1960, 25, 789. (c) Sato, Y.; Ikekawa, N. J. Org. Chem. 1961, 26, 5058.

10. Iglesias-Arteaga, M. A.; Pérez Martínez, C. S.; Coll Manchado, F. Synth. Commun. 2000, 30(1) 163. (in this publication the name given to this compound was in error, it reads isochiapagenin acetate and should read rockogenin acetate).

11. (a) Iglesias-Arteaga, M. A.; Pérez Gil, R.; Pérez Martínez, C. S.; Coll Manchado, F. J. Chem. Res. (S). 1999, 48. (b) Viñas-Bravo, O.; Hernández-Linares, G.; Mata-Esma, M. Y.; Martínez-Pascual, R.; Montiel-Smith, S.; Meza-Reyes, S.; Bernès, S.; Sandoval-Ramírez, J.; Iglesias-Arteaga, M. A. ARKIVOC 2003, (xi), 163.

12. (a) Turner, R. B. J . Am. Chem. Soc. 1950, 72, 878. (b) Gallagher, T. F.; Kritchevsky, T. H. J . Am. Chem. Soc. 1950, 72, 882. (c) Mislow, K.; Brenner, J. J . Am. Chem. Soc. 1953, 75, 2318.

13. Marker, R. E.; Shabica, A. J. Am. Chem Soc. 1942, 64, 813.

14. (a) For PM3 method see Stewart, J. J. P. J. Comp. Chem. 1989, 10, 209. (b) Stewart, J. J. P. J. Comp. Chem. 1989, 10, 221. (c) Stewart, J. J. P. J. Comp. Chem. 1991, 12, 320. (d) For MOPAC software see. Stewart, J. J. P. J. Comp.-Aided Mol. Design. 1990, 4, 1. (e) All molecular graphics displayed with HyperChem v. 5.02 for Windows 95/NT. HyperCube, 1997.

15. (a) Deslongchamps, P. Stereoelectronic Effects in Organic Chemistry; Pergamon Press: Oxford, 1983; p 313. (b) Noyori, R.; Sato, T.; Kobayashi, H. Tetrahedron Lett. 1980, 21, 2569. (c) Noyori, R.; Sato, T.; Kobayashi, H. Tetrahedron Lett. 1980, 21, 2573. (d) Hawthorne, M. F.; Emmons, W. D.; McCallum, K. S. J. Am. Chem. Soc. 1958, 80, 6393.

16. (a) Fukui, K. Acc. Chem. Res. 1971, 4, 57. (b) Fleming, I. Frontier Orbitals and Organic Chemical Reactions, John Wiley \& Sons: New York, 1976. (c) Woodward, R. B.; Hoffmann, R. The Conservation of Orbital Symmetry; Verlag Chemie: Weinheim, 1970. (d) Goodman, R. M.; Kishi, Y. J. Am. Chem. Soc. 1998, 120, 9392.

17. Snowden, M.; Bermudez, A.; Kelly, D. R.; Radkiewicz-Poutsma, J. L. J. Org. Chem. 2004, $69,7148$.

18. Cobas, J. C.; Sardina, F. J. Concept. Magn. Reson. 2003, 19A, 80. See also www.mestrec.com.

19. Djerassi, C.; Yashin, R.; Rosenkranz, G. J. Am. Chem. Soc. 1952, 74, 422.

20. Marker, R. E.; Rohrmann, E. J. Am. Chem. Soc. 1939, 61, 846.

21. Mazur, Y.; Spring, F. S. J. Chem. Soc. 1954, 1223.

22. Marker, R. E.; Rohrmann E. J. Am. Chem Soc. 1940, 62, 76.

23. During initial experiments, workup (stirring for 30 min. with aqueous $\mathrm{Na}_{2} \mathrm{SO}_{3}$ followed by washings with $10 \% \mathrm{NaHCO}_{3}$ solution and brine), resulted on decreased yields of bisnorcholanic lactones and carbonates. 